\title{
Effect of different plasticizers on the properties of bio-based thermoplastic elastomer containing poly(lactic acid) and natural rubber
}

\author{
V. Tanrattanakul*, P. Bunkaew \\ Bioplastic Research Unit, Department of Materials Science and Technology, Faculty of Science, Prince of Songkla \\ University, 90112 Songkla, Thailand
}

Received 5 November 2013; accepted in revised form 25 January 2014

\begin{abstract}
Bio-based thermoplastic elastomers (TPE) containing natural rubber and poly(lactic acid) were prepared by melt blending in an internal mixer. The blend ratio was $60 \%$ of natural rubber and $40 \%$ of poly(lactic acid). Dynamic vulcanization of natural rubber was performed with the sulfur system. The $2 \mathrm{~mm}$ - thick sheet samples were prepared by compression molding. The objective of this study was to investigate the effect of plasticization of PLA on the mechanical and physical properties of the derived TPE. Four plasticizers were selected: tributyl acetyl citrate (TBAC), tributyl citrate (TBC), glycerol triacetate (GTA), and triethyl-2-acetyl citrate (TEAC). The investigated properties were the tensile properties, tear strength, thermal ageing and ozone resistance, hardness, resilience, tension set and compression set. All plasticizers increased the strain at break. TBAC and TBC increased the stress at break. All plasticizers decreased the tear strength, hardness and resilience, and slightly changed the tension and compression set. TBAC seemed to be the best plasticizer for the TPE. The presence of $4 \mathrm{pph}$ (parts per hundred resin) of plasticizer provided the highest strength and tensile toughness and the strain at break increased with the increasing plasticizer content. The plasticizers decreased the $T_{\mathrm{g}}$ and $T_{\mathrm{cc}}$ of the PLA and did not affect the degree of crystallinity of PLA in the TPE.
\end{abstract}

Keywords: biopolymers, natural rubber, poly(lactic acid), polymer blend, thermoplastic elastomer

\section{Introduction}

Bio-based polymers have recently been receiving much attention. These polymers or their monomers are derived from renewable resources and they could be biodegradable or non-biodegradable. Poly (lactic acid) or PLA is a well-known biodegradable, bio-based polymer. It has been widely used as a commodity plastic over past years. Lactic acid is the monomer for PLA and is derived from normal microbial fermentation process mainly from natural carbohydrates such as sugar or starch. Natural rubber (NR) is perhaps the oldest bio-polymer used for more than one hundred years. Although NR is mainly derived from the Hevea Rubber tree, it is not readily biodegradable. Research on the biodegradation of NR is being conducted by our research group. Recently, there was an article that reported the biodegradation of latex gloves prepared from vulcanized NR [1]. Thus a polymer blend between PLA and NR is interesting because this polymer blend is a totally bio-based polymer. Due to the brittleness of PLA, NR is used as a toughening agent for PLA [2-6]. PLA/NR blends in other forms have not been reported except from our group and we have reported on a thermoplastic natural rubber prepared from PLA and NR [7].

A thermoplastic elastomer (TPE) is an interesting polymer. It shows elastomeric properties at room

\footnotetext{
${ }^{*}$ Corresponding author, e-mail: varaporn.t@psu.ac.th

(c) BME-PT
} 
temperature and can be processed as a typical thermoplastic in the melting state. TPEs could be classified into 3 types based on preparation methods or chemical structure: (1) a triblock copolymer, (2) a thermoplastic polyurethane and (3) a polymer blend between thermoplastic and elastomer. When NR is used as the elastomer phase in type 3, this TPE is referred to as thermoplastic natural rubber (TPNR) or NR-based TPE. Generally, a typical thermoplastic has been made from polypropylene, polyethylene and polyamide and the elastomer phase has varied. In order to activate or accelerate biodegradation of NR-based TPE, a biodegradable plastic such as PLA should be employed. There are lots of publications of TPE and TPNR, but there has been no publication of a TPE prepared from a blend of PLA and NR except for the one publication [7]. This TPE could be referred to as a bio-based TPE. Generally NR in a TPE must be vulcanized during mechanical blending with the thermoplastic in order to obtain dispersed NR particles. It is still questionable that NR may be biodegradable because its backbone consists of only carbon-carbon double bonds and does not have ester linkages. Furthermore, a vulcanized NR might be more difficult to degrade due to it being crosslinked molecules. Our group is seeking to isolate some microorganisms with the potential to rapidly degrade NR and vulcanized NR. We believe that perhaps a PLA/NR bio-based TPE would be a polymer with a high possibility for biodegradation. Such a TPE would be useful for many applications. Biodegradation would perhaps first occur by removal of the PLA, then, hopefully, some microorganisms could attack the restructured NR phase.

A TPE made from PLA blended with NR shows a relatively low strain at break, i.e., less than $300 \%$, because the PLA is a brittle plastic. The strain at break of PLA is $\sim 5 \%$. The conventional TPE is made from a ductile plastic such as polypropylene, poly- ethylene or nylon. As a result, its strain at break is higher than the TPE prepared from PLA. In order to increase the strain at break, modification of NR and PLA has been considered. It has been established that mastication of NR increases the strain at break of TPE [7]. The second approach was modifications to PLA. It was assumed that a ductile PLA could increase the strain at break of TPE because PLA exists as a continuous phase. A simple method for increasing the ductility of PLA is plasticization and there are many known plasticizers of PLA such as tributyl citrate (TBC) [8-13], tributyl acetyl citrate (TBAC) $[8,9,13-15]$, triacetin or glycerol triacetate (GTA) $[9,11,16]$ and triethyl acetyl citrate (TEAC) $[8,9,17]$.

The objective of this study was to investigate the effect of plasticizers incorporated into PLA on the mechanical and physical properties of the PLA/NR TPE. Four plasticizers were selected including TBC, TEBC, TEAC and GTA. The effect of the plasticizer content was also evaluated. The characterization of TPEs was carried out by scanning electron microscopy, differential scanning calorimetry and dynamic mechanical thermal analysis.

\section{Experimental}

\subsection{Materials}

PLA Ingeo ${ }^{\circledR} 4042 D$ from NatureWorks LLC. (Minnetonka, MN, USA) and block NR (STR5CV60) from Jana Concentrated Latex Co. Ltd. (Songkhla, Thailand) were employed. Four types of plasticizers were selected: tributyl acetyl citrate (TBAC), tributyl citrate (TBC), triethyl acetyl citrate (TEAC) and glycerol triacetate (GTA). Their molecular weights are 402, 360, 318 and $218 \mathrm{~g} / \mathrm{mol}$, respectively. Their chemical structure was shown in Figure 1. All plasticizers were obtained from Sigma-Aldrich Inc. (Milwaukee, WI, USA) and used without treatment.

Commercial grade curatives for NR included sulfur, an accelerator, an activator and an antioxidant. All

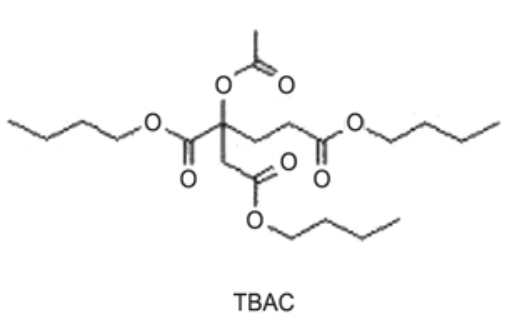

TBAC

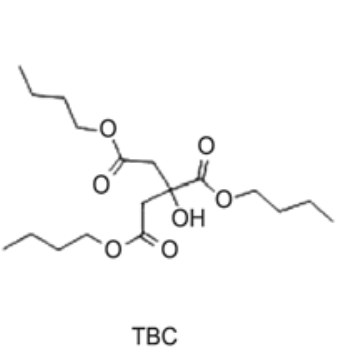

TBC
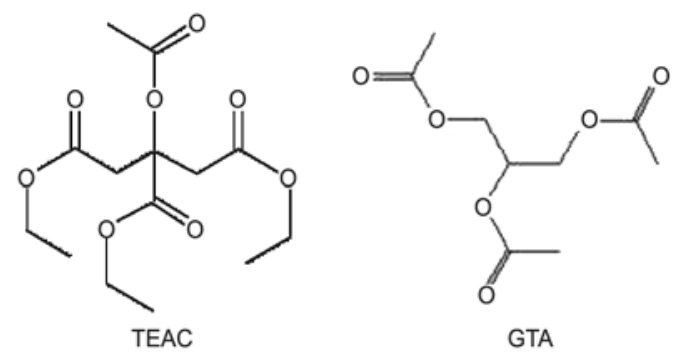

GTA

Figure 1. Chemical structure of plasticizers 
Table 1. NR compounding formula

\begin{tabular}{|l|c|}
\hline \multicolumn{1}{|c|}{ Chemical } & Weight \\
\hline NR & 100 \\
\hline Stearic acid & 2 \\
\hline Zinc oxide & 5 \\
\hline Dibenzothiazyldisulphide (MBTS) & 1.5 \\
\hline Antioixdant (Wingstay ${ }^{\circledR}$ L) & 1 \\
\hline Sulfur & 1 \\
\hline
\end{tabular}

chemicals were commercial grades and used as received. NR compound formulation was tabulated in Table 1.

\subsection{Sample preparation}

Melt blending was carried out in an internal mixer (Brabender ${ }^{\circledR}$ Mixer 350E, Duisburg, Germany) with a rotor speed of $100 \mathrm{rpm}$ at $155^{\circ} \mathrm{C}$. The ratio between the PLA and NR was $40: 60$ by weight. The plasticizer was weighted according to parts per 100 parts of the blend (pph). The content of the curatives was based on the NR. NR was primarily loaded and masticated for $1 \mathrm{~min}$ before adding the PLA. The plasticizer was mixed with PLA before being loaded into the internal mixer. Curatives were added at the last step when a constant torque was obtained after adding PLA. The residence time in the internal mixer was 420-600 s. Compression molding was carried out (Kao Tieh (KT7014), Taipei, Taiwan) at $155^{\circ} \mathrm{C}$ under a pressure of $0.3 \mathrm{~kg} / \mathrm{m}^{2}$ for $420 \mathrm{~s}$ followed by a pressing at room temperature for $600 \mathrm{~s}$ to obtain a $2 \mathrm{~mm}$ thick sheet. The blends were kept in a desiccator before testing.

\subsection{Testing of physical properties}

All physical properties including the tensile properties, tear strength, tension set, compression set, thermal ageing and ozone resistance, hardness and resilience were carried out according to the ASTM listed in Table 2. The tensile properties, tear resistance and tension set were tested at a crosshead speed of $500 \mathrm{~mm} / \mathrm{min}$. The thermal ageing and ozone resist- ance were reported in terms of changes in the tensile properties after testing. The thermal aging resistance test was performed at $70^{\circ} \mathrm{C}$ for 7 days. The ozone exposure was carried out under a concentration of 50 parts per hundred million (pphm) at $40^{\circ} \mathrm{C}$ for $6 \mathrm{~h}$. The percentage change $(\Delta)$ in the tensile properties (the tensile strength and the strain at break) was calculated according to Equation (1):

$\Delta(\%)=\frac{A-O}{O} \cdot 100$

where $O$ was the original value, and $A$ was the value after ageing by heat or ozone. Increases are indicated as positive and decreases as negative. The tension set and the compression set were calculated according to Equations (2) and (3), respectively:

Tension set $[\%]=100 \cdot \frac{L_{1 \mathrm{~T}}-L_{0 \mathrm{~T}}}{L_{0 \mathrm{~T}}}$

Compression set [\%] $=\frac{T_{0 \mathrm{C}}-T_{1 \mathrm{C}}}{T_{0 \mathrm{C}}-T_{2 \mathrm{C}}} \cdot 100$

where $L_{0 \mathrm{~T}}$ was the initial length $(20 \mathrm{~mm})$ before testing and $L_{1 \mathrm{~T}}$ was the length after testing. For the compression set test, $T_{0 \mathrm{C}}$ was the initial thickness of the specimen $(12.5 \mathrm{~mm}), T_{1 \mathrm{C}}$ was the specimen thickness after testing and $T_{2 \mathrm{C}}$ was the thickness of a test bar (9.4 mm).

\subsection{Material characterizations}

Thermal analysis was conducted using a differential scanning calorimeter (DSC) (Perkin Elmer ${ }^{\mathbb{B}}$ DSC7, Norwalk, CT, USA) in a nitrogen atmosphere. The samples were heated from 30 to $100^{\circ} \mathrm{C}$ at a heating rate of $10^{\circ} \mathrm{C} / \mathrm{min}$. The heat of fusion of the pure crystalline PLLA $\left(\Delta H_{\mathrm{c}}\right)$ was $93 \mathrm{~J} / \mathrm{g}$ [2]. A Rheometric Scientific ${ }^{\circledR}$ DMTA V (Piscataway, NJ, USA) was used for determination of the dynamic mechanical thermal analysis (DMTA) under the following condition: frequency $1 \mathrm{~Hz}$, heating rate $3^{\circ} \mathrm{C} / \mathrm{min}$, strain

Table 2. Mechanical and physical testing methods

\begin{tabular}{|c|c|c|c|}
\hline Property & Test method & Equipment & Manufacturer \\
\hline Tensile properties & ASTM D412 C & \multirow{3}{*}{ Instron $^{\circledR} 5569$} & \multirow{3}{*}{ Bucks, UK } \\
\hline Tear resistance & ASTM D624 C & & \\
\hline Tension set & ASTM D412 & & \\
\hline Compression set & ASTM D395 & Memmert ${ }^{\circledR} 400$ Air Oven & Schwabach, Germany \\
\hline Thermal ageing resistance & ASTM D573 & Tabai $\left.^{(}\right)$gphh-200 Geer Oven & Taipei, Taiwan \\
\hline Ozone resistance & ASTM D1149 & Toyosieki ${ }^{\circledR}$ EG2001 & Tokyo, Japan \\
\hline Hardness Shore A & ASTM D2240 & Shore Durameter ${ }^{(B)}$ PTC408 & New York, USA \\
\hline Resilience (vertical rebound) & ASTM D2632 & Shore Resiliometer ${ }^{\mathbb{R}}$ SRI74000 & New York, USA \\
\hline
\end{tabular}


control $0.01 \%$ and dual cantilever mode. Scanning electron micrographs were recorded using a JEOL ${ }^{\circledR}$ JSM5800LV (Tokyo, Japan). All specimens were immersed in liquid nitrogen for $6 \mathrm{hr}$ and immediately fractured prior to coating with gold. The NR and PLA on their fractured surfaces were etched by petroleum ether and dimethyl formamide, respectively.

\section{Results and discussion}

\subsection{Effect of plasticizer type}

\subsubsection{Mechanical properties of bio-based TPE}

In this section the plasticizer content was $4 \mathrm{pph}$. The tensile properties were the main criterion used to determine the effect of the plasticizer type on the mechanical properties of the present bio-based TPE. The stress-strain curves of TPEs with and without plasticizer are shown in Figure 2. Their tensile behavior looked similar to a typical thermoplastic elastomer such as a poly(styrene-isoprene-styrene) block copolymer [18], poly(styrene-butadiene/butylene-styrene) block copolymer [19], silicone rubber [20], PE/nitrile rubber TPE [21] and nylon-6/EPDM TPE [22]. The tensile strength or the stress at break and the strain at break of all TPEs are displayed in Figure 3. The TBAC and TBC increased the stress at break of TPE whereas the GTA decreased this prop-

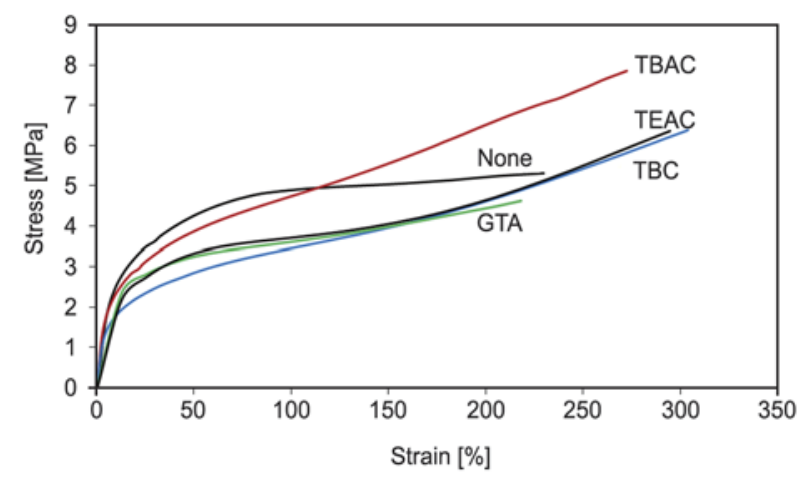

Figure 2. Stress-strain curves of TPE with and without plasticizer

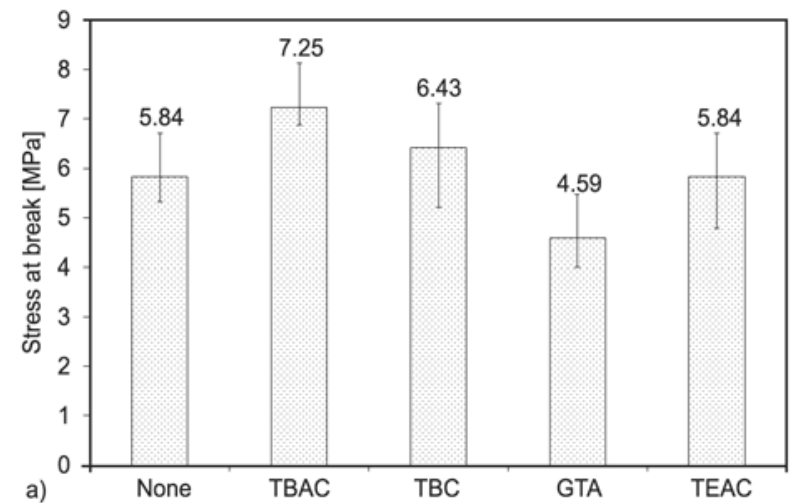

erty. TEAC had no effect on the stress at break of TPE. All plasticizers increased the strain at break. According to theory, plasticization causes a lower glass transition temperature $\left(T_{\mathrm{g}}\right)$ of the polymer matrix leading to an increase in flexibility and ductility. This was the reason for the enhancement of the strain at break. All plasticizers, except GTA, increased the tensile toughness of the TPE as indicated by the area under each stress-strain curve. TBAC, TBC and TEAC showed a high promise for increasing the tensile properties of TPE. According to Ljunberg and Wesslen [9] the solubility parameter of PLA was $20.1\left(\mathrm{~J} / \mathrm{cm}^{3}\right)^{1 / 2}$ while Kaczmarek and Vuković-Kwiatkowska [23] reported this value was in the range of $19.28-21.73\left(\mathrm{~J} / \mathrm{cm}^{3}\right)^{1 / 2}$. The solubility parameter of NR was $16.6\left(\mathrm{~J} / \mathrm{cm}^{3}\right)^{1 / 2}$ [24]. The solubility parameter of the four plasticizers was in the range of $18.0-19.6\left(\mathrm{~J} / \mathrm{cm}^{3}\right)^{1 / 2}[8,9]$. It should be noted that the solubility parameters of PLA and all plasticizers were in the same range. There is a contradiction in ranking of the solubility parameters of these plasticizers. They could be ranked as TEAC $\left(19.6\left(\mathrm{~J} / \mathrm{cm}^{3}\right)^{1 / 2}\right)>$ TBC $\left(18.8\left(\mathrm{~J} / \mathrm{cm}^{3}\right)^{1 / 2}\right)>$ TBAC $\left(18.7\left(\mathrm{~J} / \mathrm{cm}^{3}\right)^{1 / 2}\right)[8]$, or as TBC $\left(19.6\left(\mathrm{~J} / \mathrm{cm}^{3}\right)^{1 / 2}\right)>$ $\operatorname{GTA}\left(19.1\left(\mathrm{~J} / \mathrm{cm}^{3}\right)^{1 / 2}\right)>\operatorname{TEAC}\left(18.9\left(\mathrm{~J} / \mathrm{cm}^{3}\right)^{1 / 2}\right)>$ $\operatorname{TBAC}\left(18.0\left(\mathrm{~J} / \mathrm{cm}^{3}\right)^{1 / 2}\right)[9]$. The solubility of NR was lower than that of PLA and plasticizers, whereas the solubility of PLA and plasticizers were almost in the same range. This indicated that PLA should interact with plasticizers more than NR. The smallest solubility parameter of TBAC may result in the lower strain at break compared to the TPE containing TEAC and TBC. However, the rank of these solubility parameters cannot explain the lowest tensile properties of the TPE containing GTA. There are two possibilities that should be considered. Firstly, the plasticization effect of these plasticizers in TPE may not be straightforward because TPE was a polymer

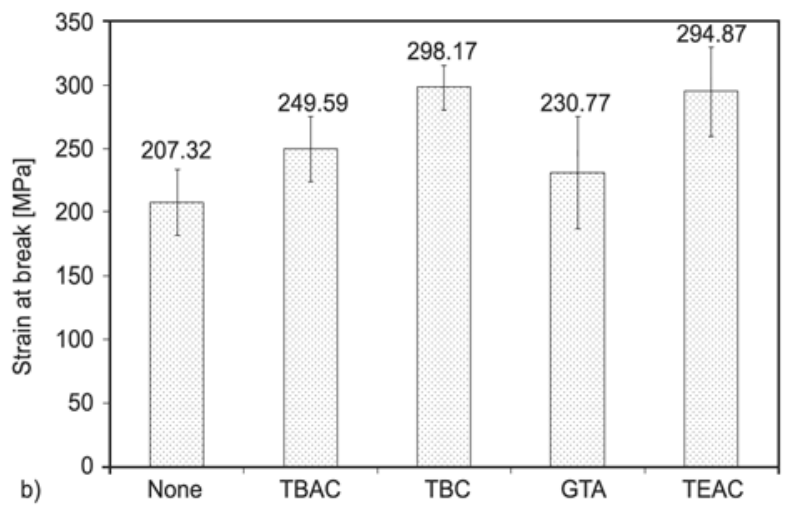

Figure 3. The effect of the plasticizer type on the tensile properties of TPE: (a) the stress at break; (b) the strain at break 


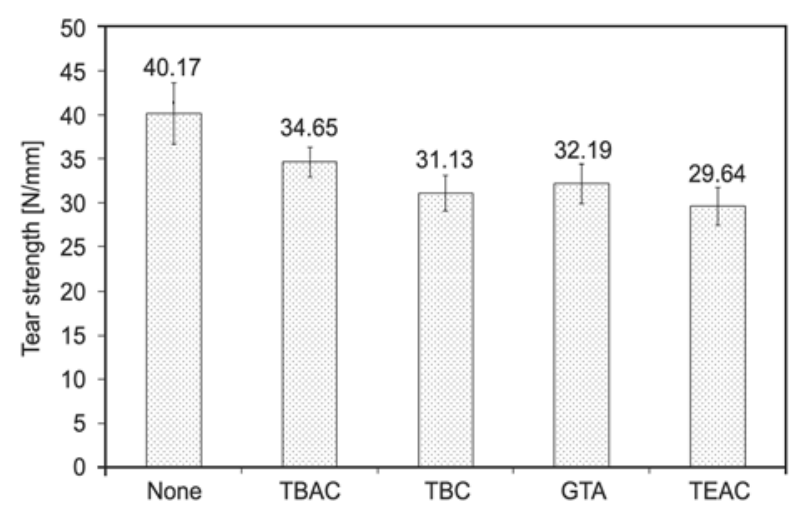

Figure 4. The effect of the plasticizer type on the tear strength of TPE

blend. The presence of the NR phase and the curing agents may interfere with the plasticization efficiency of the plasticizer. Secondly, the lowest molecular weight of GTA may cause the lowest intermolecular attraction of PLA leading to the lowest tensile strength and strain. The increment of the stress at break due to the plasticizer could be explained in view of the strain hardening of the plasticized PLA matrix as shown in Figure 2. A higher ductility and higher stress at break was obtained. GTA seemed to be the least effective plasticizer for TPE based on the tensile properties. All plasticizers decreased the tear strength as shown in Figure 4. The plasticized PLA was softer and its intermolecular attraction was reduced because of the penetration of the plasticizer molecules into the PLA matrix. This was attributed to a decrease in the tear strength when adding the plasticizer.

Table 3 represents the effect of the plasticizers on other physical properties of the TPE. Plasticization decreased the hardness Shore A and the resilience of TPE. There was no doubt that the lower hardness of TPE was derived by adding a plasticizer to the PLA matrix. The TPE containing TEAC showed a slight decrease in the hardness and that containing TBC showed a maximum decrease. Resilience is an

Table 3. The effect of plasticizers on the physical properties of TPE

\begin{tabular}{|l|c|c|c|c|}
\hline $\begin{array}{c}\text { Plasticizer } \\
\text { (4 pph) }\end{array}$ & $\begin{array}{c}\text { Hardness } \\
\text { [Shore A] }\end{array}$ & $\begin{array}{c}\text { Resilience } \\
{[\%]}\end{array}$ & $\begin{array}{c}\text { Tension set } \\
{[\%]}\end{array}$ & $\begin{array}{c}\text { Compression } \\
\text { set } \\
{[\%]}\end{array}$ \\
\hline None & $75 \pm 3$ & $45 \pm 0$ & $14.00 \pm 2.0$ & $95.9 \pm 1.3$ \\
\hline TBAC & $68 \pm 2$ & $32 \pm 1$ & $6.50 \pm 1.8$ & $95.5 \pm 0.9$ \\
\hline TBC & $63 \pm 6$ & $26 \pm 3$ & $13.10 \pm 2.1$ & $100.3 \pm 1.3$ \\
\hline GTA & $66 \pm 1$ & $26 \pm 2$ & $23.72 \pm 0.7$ & $100.1 \pm 1.8$ \\
\hline TEAC & $73 \pm 2$ & $26 \pm 2$ & $10.00 \pm 1.5$ & $109.5 \pm 0.6$ \\
\hline
\end{tabular}

interesting property of the elastomer. It indicates the ability of a build-up of heat or the damping characteristic of the elastomer. The lower resilience implied that TPE was able to absorb more energy. The increase in flexibility of the molecular backbone of PLA arising from the plasticization was attributed to more energy absorption. However, it is not acceptable to draw the conclusion that a high or low hardness/resilience is better because it depends on the applications for which it will be used. The tension set and compression set are physical properties that predict the elastomeric behavior of polymers. Both properties are a sign of the permanent or plastic deformations after tension or compression. Therefore, a low value is favorable for an elastomeric material. In the present study, the sample without plasticizer was used as a reference. An unchanged or lower value was the target. Based on this requirement, only TBAC was suitable for the present TPE. Remarkably, GTA increased the tension set of TPE while the other plasticizers decreased this property. This result indicated that GTA was not suitable for the present TPE.

Changes in the tensile properties after thermal and ozone ageing of TPE are tabulated in Table 4. These properties are important for polymers, especially for NR because its carbon-carbon double bond $(\mathrm{C}=\mathrm{C})$ is easily attacked by ozone. In theory there are two major types of molecular mechanisms occurring in polymeric molecules during thermal and ozone ageing: chain scission and crosslinking. It was not the aim of the present study to identify the degradation mechanisms. It was our objective to obtain the minimum change in both the positive and negative value. Although a positive value means an increase in the property, an increased value may not be desirable. Therefore, the least change in view of the absolute value compared with the TPE without plasticizer was considered. TBAC was the best plasticizer for thermal ageing and ozone resistance. Concern-

Table 4. The effect of plasticizers on the thermal and ozone ageing resistance of TPE

\begin{tabular}{|c|c|c|c|c|}
\hline \multirow{2}{*}{$\begin{array}{c}\text { Plasticizer } \\
\text { (4 pph) }\end{array}$} & \multicolumn{2}{|c|}{ Thermal ageing } & \multicolumn{2}{|c|}{ Ozone ageing } \\
\hline & $\begin{array}{l}\Delta \delta_{\mathrm{b}} \\
{[\%]}\end{array}$ & $\begin{array}{c}\Delta \varepsilon_{\mathrm{b}} \\
{[\%]}\end{array}$ & $\begin{array}{l}\Delta \delta_{\mathrm{b}} \\
{[\%]}\end{array}$ & $\begin{array}{r}\Delta \varepsilon_{\mathbf{b}} \\
{[\%]}\end{array}$ \\
\hline None & 2.2 & 14.3 & 8.7 & -26.5 \\
\hline TBAC & -8.5 & 14.7 & -25.5 & -6.2 \\
\hline TBC & -30.6 & -29.3 & -30.4 & -27.8 \\
\hline GTA & 12.4 & 19.9 & -32.0 & -84.3 \\
\hline TEAC & -30.8 & -28.2 & -25.0 & -26.5 \\
\hline
\end{tabular}


ing the resistance to thermal ageing, the change in the strain at break of the TBAC-sample was similar to that of the None-sample and its stress at break was decreased by less than $10 \%$. All plasticizers led to a reduction in the stress at break in the range of -25 to $-32 \%$ after ozone exposure. The TBAC-sample showed the least change in the strain at break $(-6 \%)$ whereas the other samples had high reduction values such as -27 or $-84 \%$. Consequently, TBAC seemed to be the best plasticizer for the present TPE in terms of the mechanical properties of the TPE.

All plasticizers used in the present study had been already selected because they were known for their ability to plasticize PLA. The effect of these plasticizers on the transition temperature of PLA in the TPE was also established as described in the following section. Although these plasticizers did not affect the transition temperature of NR, their effect on the mechanical properties of NR in terms of the lubrication effect was also considered. The TPE in the present study was complex because there were two polymeric phases. Thus, the affinity between a plasticizer and each polymer (PLA and NR) and any interactions between the plasticizer and the curatives were our concern. This consideration needs to be studied in detail but it was not in the scope of the present study.

\subsubsection{Characteristics of bio-based TPE}

TPE behaves like an elastomer at room temperature and it can be melted like a thermoplastic. Therefore, TPE is widely used in the products need some rubber elasticity and can be thermally recycled or

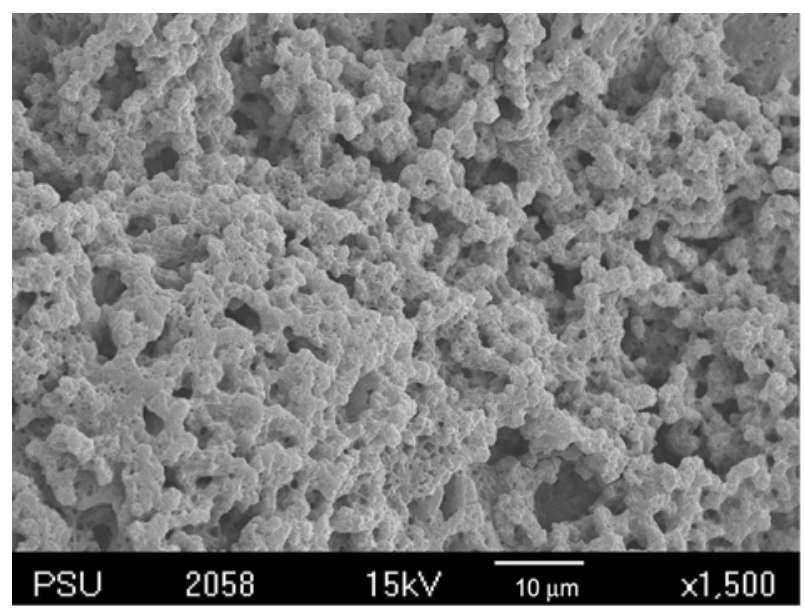

a) processed with thermoplastic equipment. The characteristics of TPE made from a polymer blend are primarily controlled by the blend morphology. Normally the plastic content is less than the rubber content for the preparation of TPE in order to receive the rubber characteristic. Theoretically the major component becomes a continuous phase in the polymer blend. In order to make a phase inversion in the present study, NR which was the major component became the dispersed phase by a dynamic vulcanization where NR became vulcanized during blending with PLA. Figure 5 confirmed the occurrence of the dynamic vulcanization. Dispersed NR particles were observed in the sample etched with dimethyl formamide, a good solvent for PLA and a non-solvent of NR (Figure 5a). Figure 5b represents the SEM micrograph of the sample etched with petroleum ether, a good solvent of NR. The continuous phase of PLA was remarkable and some crosslinked NR particles that were unable to be dissolved were also observed. Actually we also did a preliminary test to investigate the vulcanization of NR itself in the internal mixer. NR was able to undergo vulcanization under this blending condition. Furthermore, we had already determined the recyclability of the TPE, i.e., its ability to return to its original form (not shown here).

The thermal properties of TPE investigated by DSC are demonstrated in Figure 6. DSC thermograms were recorded from the first heating scan. A double melting peak of PLA was observed that was similar to the blend of PLA containing $10 \%$ of NR $[2,3]$. Their glass transition temperature $\left(T_{\mathrm{g}}\right)$, cold crystallization temperature $\left(T_{\mathrm{cc}}\right)$ and melting temperatures

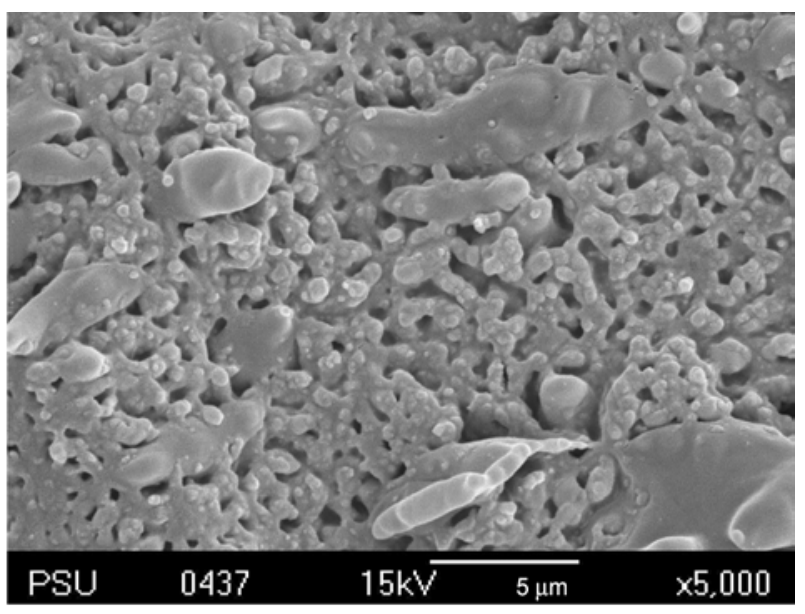

b)

Figure 5. SEM micrographs of TPE: (a) etched with dimethyl formamide showing the NR particles; (b) etched with petroleum ether showing PLA continuous phase and some remained dispersed NR particles 


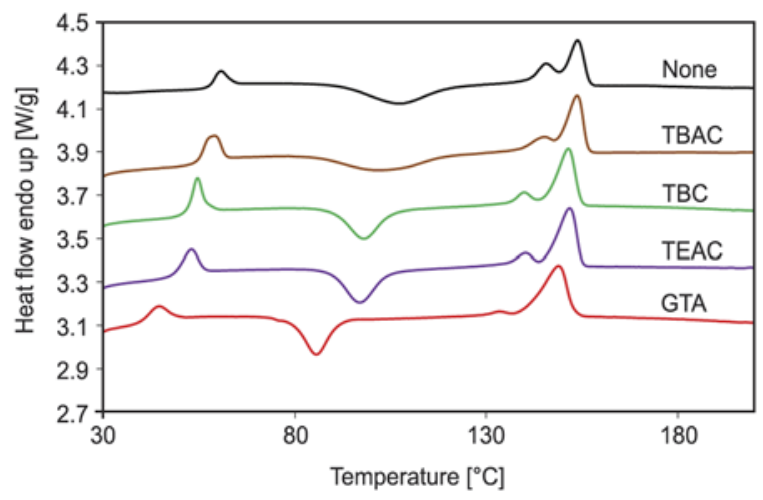

Figure 6. DSC thermograms of TPE with and without plasticizer

are listed in Table 5. All plasticizers significantly decreased the $T_{\mathrm{g}}$ and $T_{\mathrm{cc}}$ of PLA, and GTA showed the most effectiveness in plasticization because it produced the lowest $T_{\mathrm{g}}$ and $T_{\mathrm{cc}}$. Only GTA seemed to influence the $T_{\mathrm{m}}$ of the PLA whereas the others showed only a slight decrease in the $T_{\mathrm{m}}$. The degree of crystallinity of PLA did not change due to the plasticization, and their degree of crystallinity was in the range of $21-22 \%$. The plasticizers enhanced the chain flexibility of PLA resulting in a faster cold crystallization process (lower $T_{\mathrm{cc}}$ ). It was assumed that the cold crystallization contributed to the double melting peak. The lower melting peak belonged to the crystals from the cold crystallization process. The higher one was from the original crystals derived from the sample preparation. The significant drop in $T_{\mathrm{m}}$ by GTA implied the presence of smaller sized crystals or more defects in the crystals but the degree of crystallinity remained constant. It is generally known that short chain polymer can crystallize faster than long chain polymer but the crystals containing more chain ends in the crystalline structure could be a defect in its crystal and resulted in low $T_{\mathrm{m}}$. The tension set in Table 2 was also evidence indicating more plastic deformation caused by the short chain PLA in the TPE containing GTA. This might have an impact on the low tensile strength of this TPE as well. It seemed that the molecular weight of the plasticizers had a strong effect on the $T_{\mathrm{g}}$ and $T_{\mathrm{cc}}$ of PLA. The lower the molecular weight of the plasticizer, the lower was the $T_{\mathrm{g}}$ and $T_{\mathrm{cc}}$ of the PLA. The lowest $T_{\mathrm{g}}$ of the TPE containing GTA may contribute to the lowest tensile strength and strain at break of the TPE.

Figure 7 exemplifies the temperature dependence of the loss tangent $(\tan \delta)$ of the TPEs derived from DMTA. All TPEs showed two remarkable $\alpha$ transition temperatures that were equivalent to the $T_{\mathrm{g}}$ of NR and PLA and are listed in Table 4. Pure PLA had a $T_{\mathrm{g}}$ of $79.6^{\circ} \mathrm{C}$ and was in the same range as the $T_{\mathrm{g}}$ of PLA in the TPE without plasticizers $\left(78.7^{\circ} \mathrm{C}\right)$. The $T_{\mathrm{g}}$ of the PLA phase in the TPE was much decreased by plasticization. In a similar observation to the DSC result, GTA yielded the lowest $T_{\mathrm{g}}$ of PLA. Although GTA provided the lowest $T_{\mathrm{g}}$ it did not provide better mechanical properties than other plasticizers. As a result, from the present study GTA was not the best plasticizer. The $T_{\mathrm{g}}$ of the NR phase did not change significantly. It showed a broad peak and the temperature was in the range of -56 to $-52^{\circ} \mathrm{C}$. This result substantiated the assumption that the plasticizers did not affect the thermal transition of NR. Obviously, the plasticizers increased the $\tan \delta$ of the PLA phase and decreased that of NR phase. This behavior was related to the molecular weight of the plasticizers. The lower molecular weight pro-

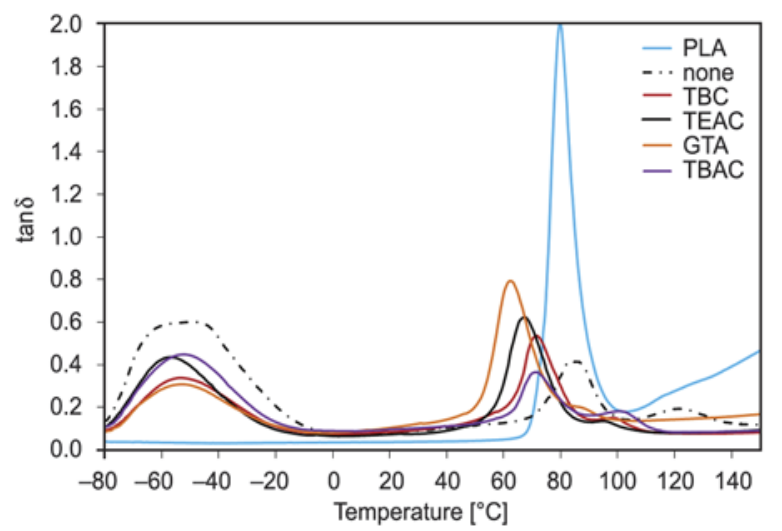

Figure 7. Loss tangent of TPE with and without plasticizer

Table 5. The effect of plasticizers on the transition temperature of TPE

\begin{tabular}{|c|c|c|c|c|c|c|}
\hline \multirow{2}{*}{$\begin{array}{l}\text { Plasticizer } \\
\text { (4 pph) }\end{array}$} & \multicolumn{4}{|c|}{ DSC $^{\mathbf{a}}$} & \multicolumn{2}{|c|}{ DMTA } \\
\hline & $\begin{array}{c}\mathbf{T}_{\mathbf{g}} \\
{\left[{ }^{\circ} \mathbf{C}\right]}\end{array}$ & $\begin{array}{c}\mathbf{T}_{\mathbf{c c}} \\
{\left[{ }^{\circ} \mathbf{C}\right]}\end{array}$ & $\begin{array}{c}\mathbf{T}_{\mathbf{m}} \\
{\left[{ }^{\circ} \mathbf{C}\right]}\end{array}$ & $\% X_{c}$ & $\begin{array}{l}T_{\text {g-NR }} \\
{\left[{ }^{\circ} \mathbf{C}\right]}\end{array}$ & $\begin{array}{l}\text { T }_{\text {g-PLA }} \\
{\left[{ }^{\circ} \mathrm{C}\right]}\end{array}$ \\
\hline None & 60.5 & 106.8 & $145.5 / 153.8$ & 21.42 & -54.4 & 78.7 \\
\hline TBAC & 58.8 & 101.3 & $145.1 / 153.6$ & 21.60 & -52.2 & 71.2 \\
\hline TBC & 54.5 & 98.0 & $140.0 / 151.3$ & 21.58 & -53.7 & 71.3 \\
\hline GTA & 44.3 & 85.5 & $133.3 / 148.8$ & 22.14 & -52.8 & 62.2 \\
\hline TEAC & 52.8 & 96.8 & $140.1 / 151.6$ & 22.39 & -56.0 & 67.6 \\
\hline
\end{tabular}

${ }^{\mathrm{a}}$ Thermal properties of PLA phase 
vided more changes. It should be noted that the PLA phase in TPE showed another transition temperature above its $\alpha$ transition $\left(T_{\mathrm{g}}\right)$ and this transition temperature shifted to a lower temperature after plasticization. This transition has also been seen in the PLA blended with $10 \%$ NR [2]. It might be involved with the cold crystallization process.

\subsection{Effect of the plasticizer content}

In this section, two plasticizers were selected for determination of the effect of the plasticizer content. TBAC was used because it provided the best properties. TBC was used for a cross check of the optimal content. Figure 8 shows the effect of the plasticizer content on the stress-strain curve of TPE and the mechanical properties of these TPEs are listed in Table 6. Obviously, 4 pph was the optimal content for both plasticizers. The strain at break of TPE increased with the increasing TBAC content. The modulus at $300 \%\left(E_{300 \%}\right)$ or the stress at $300 \%$ strain appeared at a TBAC content $\geq 6 \mathrm{pph}$. The area under the stress-strain curve could be used to predict the energy absorbed for the material failure and designated as the tensile toughness. The $4 \mathrm{pph}$ of TBAC provided the maximum tensile toughness and the

Table 6. The effect of the plasticizer content on the mechanical properties of TPE

\begin{tabular}{|l|c|c|c|c|c|}
\hline \multicolumn{2}{|l|}{ Plasticizer content } & $\begin{array}{c}\mathbf{E}_{\mathbf{3 0 0} \%} \\
{[\mathbf{M P a}]}\end{array}$ & $\begin{array}{c}\mathbf{\sigma}_{\mathbf{b}} \\
{[\mathbf{M P a}]}\end{array}$ & $\begin{array}{c}\mathbf{\varepsilon}_{\mathbf{b}} \\
{[\%]}\end{array}$ & $\begin{array}{c}\text { Tear } \\
\text { strength } \\
{[\mathbf{N} / \mathbf{m m}]}\end{array}$ \\
\hline None & $0 \mathrm{pph}$ & 0.00 & $5.5 \pm 0.5$ & $207 \pm 26$ & $40.2 \pm 3.5$ \\
\hline \multirow{4}{*}{ TBAC } & $2 \mathrm{pph}$ & 0.00 & $5.0 \pm 0.7$ & $275 \pm 34$ & $21.3 \pm 3.0$ \\
\cline { 2 - 6 } & $4 \mathrm{pph}$ & 0.00 & $7.3 \pm 1.2$ & $250 \pm 26$ & $34.7 \pm 1.7$ \\
\cline { 2 - 6 } & $6 \mathrm{pph}$ & $4.3 \pm 2.7$ & $5.6 \pm 0.8$ & $326 \pm 33$ & $24.8 \pm 1.0$ \\
\cline { 2 - 6 } & $8 \mathrm{pph}$ & $4.1 \pm 5.7$ & $5.6 \pm 0.9$ & $412 \pm 54$ & $20.9 \pm 1.0$ \\
\hline \multirow{4}{*}{ TBC } & $2 \mathrm{pph}$ & 0.00 & $4.1 \pm 0.6$ & $114 \pm 7$ & $29.4 \pm 3.4$ \\
\cline { 2 - 6 } & $4 \mathrm{pph}$ & 0.00 & $6.4 \pm 0.6$ & $298 \pm 18$ & $31.1 \pm 2.0$ \\
\cline { 2 - 6 } & $6 \mathrm{pph}$ & 0.00 & $5.4 \pm 0.8$ & $281 \pm 42$ & $26.2 \pm 2.3$ \\
\cline { 2 - 6 } & $8 \mathrm{pph}$ & $3.6 \pm 0.2$ & $4.5 \pm 0.8$ & $413 \pm 37$ & $24.5 \pm 1.8$ \\
\hline
\end{tabular}

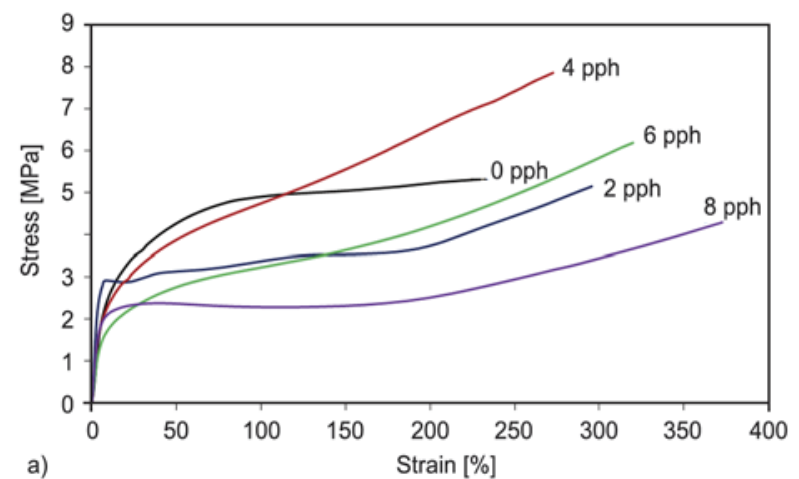

maximum tear strength. The hardness of the TPE decreased with any further increase of the TBAC content while the resilience decreased when the TBAC content $\geq 6$ pph (Table 7). The TBAC content did not show any significant effect on the tension set and the compression set of TPE. Although the $4 \mathrm{pph}$ of TBAC provided the maximum strength and tensile toughness, it also produced the lowest strain at break. The $6-8$ pph of TBAC would be appropriate for applications requiring $E_{300 \%}$.

The effect of TBC on the tensile behavior of TPE was different from that of the TBAC. Deplasticization may occur in the sample containing $2 \mathrm{pph}$ and this may have caused the lower tensile properties. The strain at break increased with the increasing TBC content, except at 4 and $6 \mathrm{pph}$ when the values were the same. The stress at break was highest at $4 \mathrm{pph}$ and, then, decreased with the increasing TBC content.

Table 7. The effect of the TBAC content on the physical properties of TPE

\begin{tabular}{|c|c|c|c|c|}
\hline $\begin{array}{c}\text { TBAC } \\
\text { content } \\
\text { (pph) }\end{array}$ & $\begin{array}{c}\text { Hardness } \\
\text { [Shore A] }]\end{array}$ & $\begin{array}{c}\text { Resilience } \\
{[\%]}\end{array}$ & $\begin{array}{c}\text { Tension set } \\
{[\%]}\end{array}$ & $\begin{array}{c}\text { Compression } \\
\text { set } \\
{[\%]}\end{array}$ \\
\hline 0 & $75 \pm 3$ & $45 \pm 0$ & $14.0 \pm 2.0$ & $95.9 \pm 1.4$ \\
\hline 2 & $72 \pm 4$ & $47 \pm 1$ & $8.6 \pm 0.8$ & $85.9 \pm 3.1$ \\
\hline 4 & $68 \pm 2$ & $32 \pm 1$ & $6.5 \pm 1.8$ & $95.5 \pm 0.9$ \\
\hline 6 & $66 \pm 2$ & $34 \pm 1$ & $14.4 \pm 0.5$ & $94.5 \pm 2.3$ \\
\hline 8 & $58 \pm 1$ & $34 \pm 2$ & $11.8 \pm 1.0$ & $98.9 \pm 1.4$ \\
\hline
\end{tabular}

Table 8. The effect of the TBC content on the physical properties of TPE

\begin{tabular}{|c|c|c|c|c|}
\hline $\begin{array}{c}\text { TBC } \\
\text { content } \\
\text { (pph) }\end{array}$ & $\begin{array}{c}\text { Hardness } \\
\text { [Shore A] }]\end{array}$ & $\begin{array}{c}\text { Resilience } \\
{[\%]}\end{array}$ & $\begin{array}{c}\text { Tension set } \\
{[\%]}\end{array}$ & $\begin{array}{c}\text { Compression } \\
\text { set } \\
{[\%]}\end{array}$ \\
\hline 0 & $75 \pm 3$ & $45 \pm 0$ & $14.0 \pm 2.0$ & $95.9 \pm 1.3$ \\
\hline 2 & $73 \pm 2$ & $43 \pm 2$ & $11.4 \pm 1.0$ & $90.1 \pm 2.1$ \\
\hline 4 & $63 \pm 6$ & $26 \pm 3$ & $13.1 \pm 6.1$ & $100.3 \pm 1.3$ \\
\hline 6 & $65 \pm 2$ & $24 \pm 0$ & $8.9 \pm 1.4$ & $93.2 \pm 3.5$ \\
\hline 8 & $63 \pm 4$ & $28 \pm 3$ & $13.3 \pm 1.7$ & $98.7 \pm 3.8$ \\
\hline
\end{tabular}

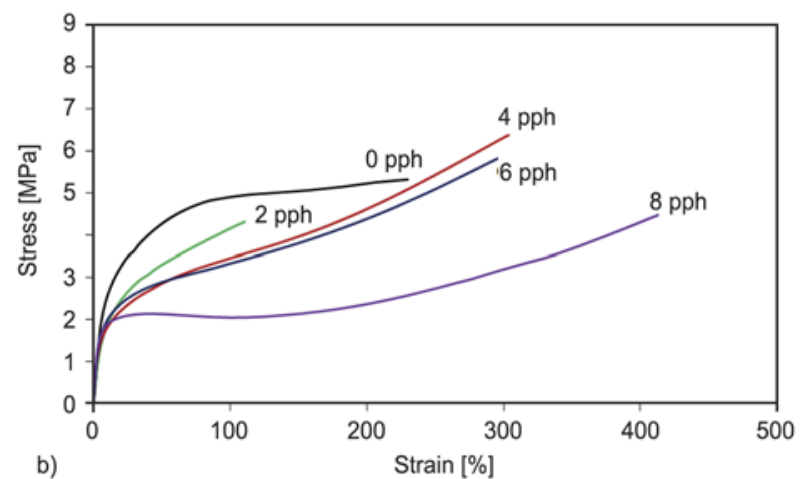

Figure 8. Stress-strain curves of TPE containing different plasticizer content: (a) TBAC; (b) TBC 
It required a greater quantity of $\mathrm{TBC}$ than $\mathrm{TBAC}$ to obtain the strain at break $>300 \%$. The 2 pph of TBC slightly changed the hardness and resilience of TPE. These properties were decreased slightly and tended to be in the same range when the TBC content increased (Table 8). The TBC content also had a slight effect on the tension set and the compression set of TPE.

The experimental results indicated that the $4 \mathrm{pph}$ of plasticizer offered the strongest and toughest TPE. Due to a variety of possible TPE applications, the specification of the mechanical and physical properties should be based on the product applications. For that reason, the plasticizer content could be $\geq 4$ pph depending on the product specification.

\section{Conclusions}

A bio-based thermoplastic elastomer from PLA blended with NR was developed. Dynamic vulcanization took place during the melt blending and this was attributed to the phase inversion in the polymer blends. Thus the blends behaved as an elastomer in view of their mechanical and physical properties and as a thermoplastic due to their recyclability. Plasticization of PLA produced significant effects on the mechanical and physical properties of the TPE. It was required to plasticize PLA in order to obtain the modulus at $300 \%\left(E_{300 \%}\right)$. All plasticizers increased the strain at break of TPE. The tensile strength of TPE, except for the one containing glyceral triacetate (GTA), also increased after plasticization. Changes in the mechanical and physical properties of TPE depended on the plasticizer type. Solubility parameter and molecular weight of plasticizers played a role on the tensile properties and transition temperature of TPE. The presence of plasticizer decreased the hardness, the resilience and the tear strength of TPE because of the increase in chain mobility/flexibility of PLA. Tributyl acetyl citrate (TBAC) was the best plasticizer used in the present study. The appropriate plasticizer content should be $\geq 4$ pph depending on the desired properties.

\section{Acknowledgements}

This project is financially supported by National Innovation Agency Thailand (Grant no. BP33/52, Project no. C49-52) and the Faculty of Science Research Fund, Prince of Songkla University. Thanks to Dr. Brian Hodgson for assistance with the English.

\section{References}

[1] Watcharakul S., Umsakul K., Hodgson B., Chumeka W., Tanrattanakul V.: Biodegradation of a blended starch/natural rubber foam biopolymer and rubber gloves by Streptomyces coelicolor CH13. Electronic Journal of Biotechnology, 15, 1-10 (2012).

DOI: $10.2225 /$ vol15-issue 1-fulltext-10

[2] Jaratrotkamjorn R., Khaokong C., Tanrattanakul V.: Toughness enhancement of poly(lactic acid) by melt blending with natural rubber. Journal of Applied Polymer Science, 124, 5027-5036 (2102).

DOI: $10.1002 /$ app.35617

[3] Chumeka W., Tanrattanakul V., Pilard J-F., Pasetto P.: Effect of poly(vinyl acetate) on mechanical properties and characteristics of poly(lactic acid)/natural rubber blends. Journal of Polymers and the Environment, 21, 450-460 (2013).

DOI: $10.1007 / \mathrm{s} 10924-012-0531-5$

[4] Suksut B., Deeprasertkul C.: Effect of nucleating agents on physical properties of poly(lactic acid) and its blend with natural rubber. Journal of Polymers and the Environment, 19, 288-296 (2011).

DOI: $10.1007 / \mathrm{s} 10924-010-0278-9$

[5] Bitinis N., Verdejo R., Cassagnau P., Lopez-Manchado M. A.: Structure and properties of polylactide/natural rubber blends. Materials Chemistry and Physics, 129, 823-831 (2011).

DOI: $10.1016 /$ j.matchemphys.2011.05.016

[6] Kowalczyk M., Piorkowska E.: Mechanisms of plastic deformation in biodegradable polylactide/poly $(1,4-$ cis-isoprene) blends. Journal of Applied Polymer Science, 124, 4579-4589 (2012).

DOI: 10.1002/app.35489

[7] Tanrattanakul V., Bunkaew P., Boonlong N.: Influence of rubber mastication on mechanical properties of poly(lactic acid)-based thermoplastic natural rubber. Journal of Biobased Materials and Bioenergy, 6, 573579 (2012).

DOI: $10.1166 / \mathrm{jbmb} .2012 .1259$

[8] Labrecque L. V., Kumar R. A., Davé V., Gross R. A., Mccarthy S. P.: Citrate esters as plasticizers for poly (lactic acid). Journal of Applied Polymer Science, 66, 1507-1513 (1997).

DOI: $10.1002 /($ SICI) 1097-4628(19971121)66:8<1507 $\because$ AID-APP11>3.0.CO;2-0

[9] Ljungberg N., Wesslén B.: The effects of plasticizers on the dynamic mechanical and thermal properties of poly(lactic acid). Journal of Applied Polymer Science, 86, 1227-1234 (2002).

DOI: 10.1002/app.11077

[10] Ljungberg N., Wesslén B.: Tributyl citrate oligomers as plasticizers for poly (lactic acid): Thermo-mechanical film properties and aging. Polymer, 44, 7679-7688 (2003).

DOI: $10.1016 /$ j.polymer.2003.09.055 
[11] Ljungberg N., Andersson T., Wesslén B.: Film extrusion and film weldability of poly(lactic acid) plasticized with triacetine and tributyl citrate. Journal of Applied Polymer Science, 88, 3239-3247 (2003). DOI: 10.1002/app.12106

[12] Ljungberg N., Wesslén B.: Preparation and properties of plasticized poly(lactic acid) films. Biomacromolecules, 6, 1789-1796 (2005).

DOI: $10.1021 / \mathrm{bm} 050098 \mathrm{f}$

[13] Harte I., Birkinshaw C., Jones E., Kennedy J., DeBarra E.: The effect of citrate ester plasticizers on the thermal and mechanical properties of poly(DL-lactide). Journal of Applied Polymer Science, 127, 1997-2003 (2013).

DOI: $10.1002 /$ APP.37600

[14] Wang N., Zhang X., Ma X., Fang J.: Influence of carbon black on the properties of plasticized poly(lactic acid) composites. Polymer Degradation and Stability, 93, 1044-1052 (2008).

DOI: $10.1016 /$ j.polymdegradstab.2008.03.023

[15] Höglund A., Hakkarainen M., Albertsson A-C.: Migration and hydrolysis of hydrophobic polylactide plasticizer. Biomacromolecules, 11, 277-283 (2010). DOI: $10.1021 / \mathrm{bm} 901157 \mathrm{~h}$

[16] Oksman K., Skrifvars M., Selin J-F.: Natural fibres as reinforcement in polylactic acid (PLA) composites. Composites Science and Technology, 63, 1317-1324 (2003).

DOI: 10.1016/S0266-3538(03)00103-9

[17] Zhang J-F., Sun X.: Physical characterization of coupled poly(lactic acid)/starch/maleic anhydride blends plasticized by acetyl triethyl citrate. Macromolecular Bioscience, 4, 1053-1060 (2004).

DOI: $10.1002 / \mathrm{mabi} .200400076$
[18] Dair B. J., Honeker C. C., Alward D. B., Avgeropoulos A., Hadjichristidis N., Fetters L. J., Capel M., Thomas E. L.: Mechanical properties and deformation behavior of the double gyroid phase in unoriented thermoplastic elastomers. Macromolecules, 32, 8145-8152 (1999). DOI: 10.1021/ma990666h

[19] Li Y., Shimizu H.: High-shear processing induced homogenous dispersion of pristine multiwalled carbon nanotubes in a thermoplastic elastomer. Polymer, 48, 2203-2207 (2007).

DOI: $10.1016 /$ j.polymer.2007.02.066

[20] Frogley M. D., Ravich D., Wagner H. D.: Mechanical properties of carbon nanoparticle-reinforced elastomers. Composites Science and Technology, 63, 1647-1654 (2003). DOI: $10.1016 / \mathrm{S} 0266-3538(03) 00066-6$

[21] George J., Varughese K. T., Thomas S.: Dynamically vulcanised thermoplastic elastomer blends of polyethylene and nitrile rubber. Polymer, 41, 1507-1517 (2000). DOI: $10.1016 / \mathrm{S} 0032-3861(99) 00302-\mathrm{X}$

[22] Oderkerk J., Groeninckx G., Soliman M.: Investigation of the deformation and recovery behavior of nylon-6/rubber thermoplastic vulcanizates on the molecular level by infrared-strain recovery measurements. Macromolecules, 35, 3946-3954 (2002).

DOI: $10.1021 / \mathrm{ma} 010651 \mathrm{v}$

[23] Kaczmarek H., Vuković-Kwiatkowska I.: Preparation and characterization of interpenetrating networks based on polyacrylates and poly(lactic acid). Express Polymer Letters, 6, 78-94 (2012).

DOI: $10.3144 /$ expresspolymlett.2012.9

[24] Robeson L. M.: Polymer blends: A comprehensive review. Hanser, Munich (2007). 